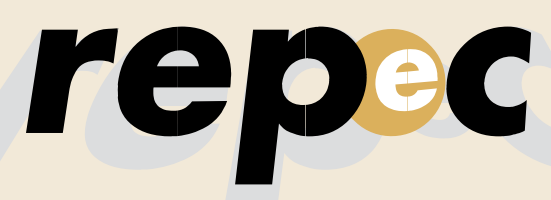

REPeC, Brasília, v. 10, n. 4, art. 1, p. 363-379, out./dez. 2016 Disponivel online em www.repec.org.br

DOl: http://dx.doi.org/10.17524/repec.v10i4.1398

\title{
O Impacto das Dimensões Culturais sobre a Prática Contábil no Brasil: um olhar a partir da Percepção dos Operadores da Contabilidade
}

\begin{abstract}
Resumo
O objetivo deste estudo foi verificar em que extensão as dimensões culturais impactam a prática contábil no Brasil. Para tanto, no que diz respeito às dimensões culturais, recorreu-se ao questionário Valued Survery Model 08 (VSM 08) adaptado construído por Hofstede em 2008, e sua versão em português. Já para a captura das práticas contábeis, recorreu-se ao questionário estruturado com perguntas diretas aos operadores da contabilidade, utilizado originalmente por Chanchani e Willett (2004) e replicado por Almeida e Lisboa (2011) e Karabinar, Canel e Öktem (2012). A amostra final contou com um total de 449 respondentes, a nível nacional, divididos nos seguintes grupos de operadores: usuários da contabilidade, professores de Contabilidade, profissionais da contabilidade e alunos de Contabilidade. Tendo em vista que há um número diversificado de variáveis para capturar as dimensões culturais e as práticas contábeis, recorreu-se à Análise Fatorial Exploratória (AFE). Os fatores foram extraídos por meio da Análise dos Componentes Principais e com a extração Varimax. Após a análise fatorial, foi realizada uma regressão múltipla com os fatores extraídos, na qual a variável dependente foram as práticas contábeis, e as variáveis independentes corresponderam às dimensões culturais. Os resultados encontrados indicam que os operadores da contabilidade são, principalmente, conservadores e as dimensões culturais que mais impactam a prática contábil são aversão à incerteza e distância do poder. Concluiu-se que não é possível inferir que, em um primeiro momento, a adoção de normas contábeis internacionais proporciona uma melhoria no processo contábil, já que os países onde essas normas originalmente foram concebidas (tradição jurídica do commom law) apresentam uma baixa aversão à incerteza e à distância do poder, algo contrário ao que foi encontrado nessa investigação.
\end{abstract}

Palavras-chave: Dimensões Culturais, Práticas Contábeis, IFRS.

\section{Bruno Jesus de Lima} Mestre em Contabilidade pela Universidade Federal da Bahia (UFBA) e Contador Pleno da Petrobras e professor do Centro Universitário Jorge Amado (Unijorge). Contato: Avenida Antônio Carlos Magalhães, $\mathrm{n}^{\circ}$ 1.113. Itaigara, Salvador, BA, CEP: 41810-560.

E-mail: brunojlima@hotmail.com 


\section{Introdução}

A necessidade de um conjunto congruente de padrões de contabilidade em nível internacional é uma constante, tendo em vista que o fluxo de capital entre países com estruturas jurídicas, econômicas e mercadológicas entre outras díspares tem aumentado significativamente nos últimos anos. Além do fluxo de capital, outros fatores motivam a corrida rumo à uniformização dos dados contábeis, entre eles, o aumento da qualidade e a transparência das informações geradas.

Apesar dessa demanda, aspectos internos e peculiares dos países devem ser considerados no processo de convergência às práticas contábeis internacionais, tais como, herança colonial, sistema legal, fonte de financiamento, sistema político e a cultura, pois eles impactam, de forma diferente e significativa, a prática contábil (reconhecimento, mensuração e evidenciação) de cada país (Chanchai \& Willett, 2004; Gray, 1988 e Nobes, 1998).

Estudos têm demonstrado que aspectos culturais afetam o ambiente de negócios dos países e que, por consequência, são determinantes à existência de diferenças nas práticas contábeis entre as nações (Gray, 1988; Chanchani \& MacGregor, 1999; Weffort, 2005; Karabinar, Canel \& Öktem, 2012; Rodriguez, 2009). Logo, há que se considerar também que os fatores culturais são determinantes à adoção das normas contábeis internacionais IFRS (International Financial Reporting Standards) emanadas pelo Iasb (Internacional Accounting Standard Boards).

No tocante ao efeito da cultura sobre o ambiente dos negócios, Hofstede (1980) propôs quatro dimensões subjacentes à cultura que mais impactam os negócios e, assim, posicionou os países que as apresentavam em maior ou menor grau. Valendo-se dessa investigação, Gray (1988) incorporou-as ao que ele clamou de "valores contábeis", capazes de refletir a prática contábil de cada país. Nesse sentido, tais valores (ou práticas contábeis, expressão que será usada daqui em diante) foram divididos em quatro perspectivas, a saber: profissionalismo, uniformidade, conservadorismo e sigilo. Além disso, Gray (1988) formulou hipóteses a serem verificadas sobre elas e posicionou os países que apresentavam predominância maior ou menor dessas práticas.

Considerando que a dinâmica da Contabilidade, refletida pela influência que sofre e exerce sobre o ambiente social e cultural onde opera, Hopwood e Miller (1994) têm acentuado, nos últimos anos, que a cultura é um elemento-padrão para o entendimento das normas e valores do sistema social. Além disso, essa dinâmica contábil pode ser um construto utilizado para explicar e prever comportamentos de indivíduos de um determinado meio social (Harrison \& McKinnon, 1986). Entender, portanto, de que maneira os operadores da contabilidade brasileiros (aqui entendido como professores, profissionais, estudantes e usuários da contabilidade) percebem isso é uma constante. Nesse sentido, tem-se o seguinte problema de pesquisa: Em que extensão as dimensões culturais impactam as práticas contábeis no Brasil?

O objetivo geral desta pesquisa consiste em verificar o impacto das dimensões culturais propostas por Hofstede (1980) sobre as práticas contábeis elencados por Gray (1988), segundo a visão dos operadores da contabilidade no Brasil. Adicionalmente, são propostos os seguintes objetivos específicos: (i) identificar como os operadores da Contabilidade no Brasil refletem as dimensões culturais propostas por Hofstede (1980); (ii) identificar como os operadores da contabilidade no Brasil refletem as práticas contábeis propostas por Gray (1988); e (iii) verificar o impacto de tais dimensões culturais sobre as práticas contábeis que refletem a sua prática no Brasil.

Além de outros, este estudo justifica-se por três pontos principais, a saber: (i) por contribuir para a ampliação das discussões a respeito das origens das diferenças entre as práticas contábeis dos países e que são, em última análise, empecilhos para a adoção plena das IFRS; (ii) por permitir comparar se as práticas contábeis adotadas no Brasil estão ou não alinhadas com o perfil cultural dos países que deram origem às IFRS - perfil este caracterizado em princípios gerais e, não, em regras procedimentais por serem voltados para o investidor; (iii) por ampliar a verificação empírica das hipóteses propostas por Gray (1988) e Hofstede (1980) no tocante à classificação dos países com base em suas dimensões culturais. 
Esta pesquisa, além desta introdução, é composta por outras quatro sessões. Na sessão seguinte, serão apresentadas a fundamentação teórica e as hipóteses; a terceira sessão é composta pelos procedimentos metodológicos; a quarta caberá às análises dos achados da investigação e, por fim, na quinta sessão, serão elencadas as considerações finais.

\section{Fundamentação Teórica}

\subsection{Aspectos Culturais na Prática Contábil: Os Estudos de Hofstede (1980)}

Em termos antropológicos, segundo Chaui (2008), cultura corresponde a um conjunto de signos e significados construídos dentro de uma sociedade e com os quais os indivíduos inseridos nesse meio estabelecem relações entre si. Esse conjunto abrange a linguagem, a religião, a sexualidade, os instrumentos e as formas do trabalho, as formas da habitação, o vestuário e a culinária, as expressões de lazer, a música, a dança, os sistemas de relações sociais, particularmente os sistemas de parentesco ou a estruturada família, as relações de poder, a guerra e a paz, a noção de vida e morte.

Partindo dessa percepção, verifica-se que esse conceito de cultura se coaduna com o proposto por Hofstede (1980), o qual a define como "uma programação coletiva da mente, capaz de permitir a distinção de um grupo humano de outro". Assim, percebe-se que a cultura é um atributo inerente a cada grupo social capaz de promover a convivência e, ao mesmo tempo, distinguir um entre outros grupos.

Em um trabalho pioneiro e abrangente, Hofstede (1980) realizou uma pesquisa visando detectar como a cultura de um dado país é impactante no ambiente dos negócios. Para isso, ele efetuou uma pesquisa com os empregados da International Business Machines (IBM), entre 1967 e 1973, lotados em mais de 50 países. A partir dos achados da investigação, Hofstede construiu quatro dimensões subjacentes à cultura que mais impactam os negócios e, a partir deles, posicionou os países que os apresentavam em maior ou menor grau. As dimensões são estas: (i) Distância do Poder (DP); (ii) Individualismo x Coletivismo (IC); (iii) Masculinidade x Feminilidade (MF); e (iv) Aversão à Incerteza (AI).

(i) Distância do Poder (DP): expressa o nível em que os membros menos poderosos de uma sociedade aceitam a desigualdade. A questão fundamental aqui é a forma como a sociedade lida com as desigualdades entre as pessoas. Essa dimensão varia entre alta e baixa. Países com DP baixa evidenciam não haver diferenças no tocante ao poder e a riqueza do cidadão. Assim, nessas sociedades, o acesso às instâncias do poder é mais aberto a todos, além de permitirem, no que diz respeito à Contabilidade, que seus próprios operadores emitam suas próprias normas. Além disso, nestas sociedades a mobilidade social é mais permeável. Por outro lado, países com DP alta indicam que os indivíduos aceitaram a existência acentuada de desigualdades de poder e de riqueza. Essas sociedades são mais tendenciosas a seguir um sistema de classe social menos flexível, que não permite mobilidade expressiva de seus cidadãos. Adicionalmente, evidenciam a centralização de poder nas mãos de um pequeno grupo privilegiado. No que diz respeito à Contabilidade, uma Distância do Poder alta proporciona a não construção de suas normas pelos próprios operadores da contabilidade. Assim, eles conferem essa atribuição a um órgãos com capacidade de construir essas normas.

(ii) Individualismo x Coletivismo (IC): para Hofstede (1980), em sociedades individualistas prevalece $\mathrm{o}$ interesse individual, e as pessoas crescem pensando no seu próprio bem. Nessas sociedades os vínculos de ajuda e companheirismo entre os indivíduos não são obrigatórios, assim eles tendem a ter uma maior liberdade para emissão de julgamento. O coletivismo refere-se a uma preferência por uma estrutura fortemente unida na sociedade, em que as pessoas podem esperar que seus parentes ou membros de um determinado grupo cuidem deles em troca de uma lealdade inquestionável. Nesse sentido, a capacidade de julgamento não é tão exercida. 
Como a Distância do Poder, ela pode variar entre baixo e alto. Sociedades com um índice IC baixo indicam ter uma maior coletividade natural, com laços estreitos entre os indivíduos. Essa cultura reforça famílias e o coletivismo em todos têm responsabilidade pelos membros de seu grupo. Por outro lado, sociedades com um índice IC alto indicam que as individualidades e direitos individuais são relevantes dentro de uma sociedade. Os profissionais da contabilidade em sociedades individualistas têm uma maior poder e valor para emissão de julgamento, ao passo que, em sociedades coletivistas, não.

(iii) Masculinidade $\mathbf{x}$ Feminilidade (MF): essa dimensão refere-se a uma preferência na sociedade para a realização, o heroísmo, a assertividade, a competitividade e a recompensa material para o sucesso. Em sociedades masculinas, tais valores são mais nítidos, enquanto em femininas não. Além disso, sociedades masculinas enfatizam a realização financeira e pessoal, ambição pelo desempenho e a tentativa em se sobressair além da competição mais acentuada entre os agentes econômicos. Os papéis, nesse tipo de sociedade, são estritamente distintos entre homens e mulheres. Sociedades femininas apresentam uma preferência para a cooperação, modéstia, cuidado dos mais frágeis e qualidade de vida.

(iv) Aversão à Incerteza (AI): expressa o grau em que os membros de uma sociedade se sentem desconfortáveis com a incerteza e a ambiguidade. A questão fundamental aqui é a forma como a sociedade lida com o fato de que o futuro não pode ser conhecido: devemos tentar controlar o futuro ou apenas deixar isso acontecer? Países que apresentam um índice alto de AI mantêm rígidos códigos de crença e de comportamento e são intolerantes com o comportamento pouco ortodoxo e ideias. Isso fica evidenciado na prática contábil, por exemplo, em países cuja regulamentação da prática contábil é bastante acentuada em regras procedimentais emanadas de uma entidade com poderes para tal. Sociedades com um AI baixo mantêm uma atitude mais flexível à regulamentação contábil e tendem a evidenciar maiores níveis de informação.

No tocante ao Brasil, conforme Figura 01, ele é classificado com baixo Individualismo e Masculinidade - indicando, assim, alta taxa de Coletividade e Feminilidade - porém uma alta Distância do Poder e Aversão à Incerteza.

\begin{tabular}{cccc}
\hline Individualismo & Distância do Poder & Aversão à Incerteza & \multicolumn{2}{c}{ Masculinidade } \\
\hline Índice & Índice & Índice & Índice \\
\hline 38 & 69 & 76 & 49 \\
\hline Baixo & Alta & Alta & Baixa \\
\hline
\end{tabular}

Figura 01. Escores do Brasil para as dimensões culturais

Fonte: Hofstede (1980)

Embora o constructo teórico de Hofstede (1980) seja bastante utilizado como plataforma teórica de estudos culturais, algumas pesquisas o têm criticado. Baskerville (2003), por exemplo, pontua alguns aspectos que não foram levados em conta, a saber: (i) a teoria de Hofstede (1980) não é ancorada em bases teóricas advindas da Sociologia e Antropologia; (ii) apesar de ser bastante citado pelo Índice de Citação em Ciências Sociais ${ }^{1}$, principalmente em Administração e Psicologia, o contrário ocorre em Sociologia e Antropologia, em que se esperavam níveis mais altos de citação; (iii) os estudos feitos são entre a segunda metade da década de 60 e início da década de 70, sendo que sua obra foi publicada na década de 80, ou seja, a defasagem temporal pode comprometer suas conclusões, ao se levar em consideração a mudança dinâmica cultural das sociedades.

Cabe salientar que, além dessas dimensões culturais expostas anteriormente, Hofstede (1980) inseriu mais outras duas, a saber: indulgência e orientação em longo prazo. Entretanto, os estudos de Gray (1988) não fazem referência a elas e, por isso, não serão estudadas aqui.

1 Tradução livre para Social Sciences Citation Index 


\subsection{Prática Contábil Conforme Gray (1988)}

Partindo da proposição teórica de Hofstede (1980), Gray (1988) construiu quatro constructos teóricos e quatro hipóteses que poderiam explicar e predizer as diferenças entre as práticas contábeis de cada país de acordo com suas dimensões culturais. Ele postula que os sistemas de práticas dos operadores da contabilidade estão relacionados com a cultura. As práticas contábeis, por sua vez, por serem um subsistema da cultura de cada país, afetam a maneira como os operadores da contabilidade executam a Ciência Contábil. Os constructos teóricos de Gray (1988) e suas hipóteses estão apresentados abaixo:

(i) Profissionalismo $\mathbf{x}$ Controle Estatal: este constructo se refere à preferência para o exercício de julgamentos individuais da profissão e à manutenção da autorregulamentação profissional. A questão fundamental aqui é verificar em que extensão os operadores da contabilidade são independentes para se autorregularem enquanto profissionais e para realizarem julgamentos. No que diz respeito à concatenação com as dimensões culturais de Hofstede (1980), verifica-se que o profissionalismo está mais fortemente relacionado ao individualismo. Isso se justifica pelo fato de haver uma preferência por um julgamento profissional independente. Por outro lado, verifica-se que esse constructo apresenta uma fraca relação com a aversão à incerteza, uma vez que a prática é muito importante, além de uma crença no jogo justo em que uma variedade de julgamentos profissionais tende a ser mais facilmente tolerada (Gray, 1988) - também, observa-se uma fraca relação entre o profissionalismo e a distância do poder, pois nesta há uma preocupação com direitos igualitários a todos, em que as pessoas dos vários níveis de poder se sintam menos ameaçadas e mais preparadas para confiar nas outras e onde existe uma convicção maior da necessidade de justificar a imposição de leis e regulamentos. Na medida em que um país é classificado como mais profissional, presume-se que os profissionais da contabilidade terão maior liberdade e autonomia para emitirem julgamentos sobre o fenômeno econômico passível de registro pela contabilidade. Por outro lado, em países com um maior controle estatal, haveria uma menor independência por parte dos profissionais da contabilidade. Apesar de Gray (1988) não ter verificado nenhuma ligação com a masculinidade, propôs a seguinte hipótese:

$\mathrm{H}_{1}$ : Quanto maior o ranking de um país em termos de individualismo e menor em termos de aversão à incerteza e à distância do poder, mais provável é a classificação em termos de profissionalismo.

(ii) Uniformidade $\mathbf{x}$ Flexibilidade: refere-se à existência de uma uniformidade das práticas contábeis executadas pelas empresas ao longo do tempo. Gray (1988) adverte que a preferência pela uniformidade é consistente em sociedade com forte aversão à incerteza, indicando uma sociedade preocupada com a lei, a ordem e códigos rígidos e escritos de comportamentos. Além disso, existe uma relação, mas não muito forte, com a distância do poder já que a imposição de leis e códigos é em caráter uniforme e emanada de um grupo detentor do poder político. Como no profissionalismo, Gray (1988) não verificou nenhuma ligação com a masculinidade e este valor contábil. No tocante à prática contábil, países mais uniformes tenderiam a operar a contabilidade de forma mais aderente ao que preconiza o normativo contábil em detrimento da essência econômica, cuja característica é mais evidente em países com normas mais baseadas em princípios gerais e onde a prática contábil é mais regulada pelos seus próprios profissionais. Partindo disso, Gray (1988) propõe a seguinte hipótese:

$\mathrm{H}_{2}$ : Quanto maior o ranking de um país em termos de aversão à incerteza e à distância do poder e menor em termos de individualismo, maior será a propensão desse país em ter regras uniformes.

(iii) Conservadorismo x Otimismo: este constructo se relaciona com a preferência por uma abor- 
dagem cautelosa e prudente dos fenômenos contábeis, a fim de lidar com a incerteza de eventos futuros, ao contrário de uma visão mais otimista, relacionados à tomada de riscos sob a forma de uma abordagem menos cautelosa. Gray (1988) explica que a ligação entre o conservadorismo e as dimensões propostas por Hofstede (1980) estão mais fortemente relacionadas com a aversão à incerteza. A preferência por mensurações mais conservadoras ao auferir os lucros é consistente à forte aversão à incerteza, que segue uma preocupação com segurança e prudência e uma necessidade perceptível em adotar medidas cautelosas para conter incertezas futuras. Com isso, Gray (1988) levanta a seguinte hipótese:

$\mathrm{H}_{3}$ : Quanto maior o ranking de um país em termos de aversão à incerteza e menor em termos de individualismo e masculinidade, maior a propensão ao conservadorismo.

(iv) Sigilo x Transparência: diz respeito à preferência pela confidencialidade e restrição da divulgação de informações sobre o negócio apenas para aqueles que financiam a empresa. O sigilo é o valor que está relacionado à quantidade de divulgações contábeis. Dessa forma, com o aumento do sigilo, a quantidade de divulgações ao público tende a cair. Gray (1988) afirma que o sigilo é consistente com uma preferência ao coletivismo, devido ao maior envolvimento com a companhia em lugar de partes externas. Além disso, a ligação íntima em sociedades com uma elevada distância do poder também é inegável, uma vez que esta dimensão é caracterizada pela restrição de informações para preservar desigualdades de poder. Assim, ele propõe a seguinte hipótese:

$\mathrm{H}_{4}$ : Quanto maior o ranking de um país em termos de aversão à incerteza e à distância do poder e quanto menor for o ranking em termos de individualismo e masculinidade, maior propensão desse país em ser sigiloso.

A Figura 2 sumariza a concatenação entre os valores contábeis de Gray (1988) e as dimensões culturais de Hofstede (1980), na qual o sinal positivo (“+”) indica uma relação direta e o sinal negativo (“-”) indica o contrário, enquanto a interrogação (“?”) indica uma relação não identificada.

\begin{tabular}{lcccc}
\hline \multicolumn{1}{c}{$\begin{array}{c}\text { Dimensões Culturais } \\
\text { (Hofstede) }\end{array}$} & \multicolumn{4}{c}{ Valores Contábeis (Gray) } \\
\cline { 2 - 5 } & Profissionalismo & Uniformidade & Conservadorismo & Sigilo \\
\hline Distância do Poder & - & + & $?$ & + \\
\hline Aversão a Incerteza & - & + & + & + \\
\hline Individualismo & + & - & - & - \\
\hline Masculinidade & $?$ & $?$ & - & - \\
\hline
\end{tabular}

Figura 2. Relação entre as dimensões culturais de Hofstede (1980) e as práticas contábeis de Gray (1988) Fonte: Baydoun e Willet (1995) - com adaptações

\subsection{Estudos Anteriores sobre a Proposição Teórica de Gray (1988)}

Segundo Chanchani e MacGregor (1999), os estudos relacionados ao impacto da cultura sobre a prática contábil pode ser dividido entre "pré-Gray" e "pós-Gray". Naquele período, observou-se a inexistência de estudos empíricos que buscassem verificar o impacto da cultura dos países nas práticas contábeis, sendo que, nessa época, havia a predominância de estudos antropológicos e mais teóricos. Por outro lado, nesse período, iniciou-se a empiricidade de estudos sobre o impacto da cultura na Contabilidade. 
Destacam-se os seguintes estudos do período "pós-Gray": Eddie (1990) classificou os países de acordo com as suas práticas contábeis adotadas por meio de índices e os relacionou com as suas dimensões culturais; Chanchani e Willett (2004), tendo por objetivo operacionalizar empiricamente as teorias de Gray (1988), efetuou uma pesquisa com contadores e usuários das informações contábeis na Nova Zelândia e na Índia. Os achados da investigação evidenciaram que o profissionalismo e a uniformidade são os constructos que mais ficaram evidentes entre os investigados, seguidos do sigilo. Ding, Jeanjean e Stolowy (2005), visando detectar de que maneira as práticas contábeis de um país podem divergir das normas internacionais de contabilidade (IFRS), evidenciaram que os aspectos culturais, mais do que os aspectos legais, são determinantes para a existência de divergências entre as práticas contábeis. Karabinar, Canel e Öktem (2012), evidenciaram, por meio de uma investigação junto a contadores turcos, que os valores contábeis que mais se sobressaíram foram, respectivamente, profissionalismo, uniformidade e sigilo.

Apesar de os achados dessas investigações irem ao encontro da proposição teórica de Gray (1988), alguns estudos, todavia, têm encontrado evidências contrárias a ela. Tsakumis (2007), visando evidenciar a existência de diferenças significaticas entre contadores Estaduninenses e Gregos, no tocante ao conservadorismo e ao sigilo, evidenciou não haver diferenças significativas; Almeida e Lisboa (2011), ao fazerem uma investigação tendo por finalidade verificar os valores culturais de Gray (1988) com os operadores da contabilidade em Portugal, evidenciaram que, embora o controle estatal seja o valor contábil mais latente entre eles, o conservadorismo e o sigilo são destoantes ao que preconiza a teoria.

\subsection{Hipóteses}

O Brasil é um País que apresenta um alto índice para distância do poder e aversão à incerteza e baixo para masculinidade e individualismo (Hofstede, 1980) - Logo, baseado nas proposições teóricas de Gray (1988), espera-se que ele apresente as seguintes práticas contábeis: alto nível de conservadorismo, sigilo (baixa evidenciação) e baixo nível de profissionalismo, autoridade e encorajamento. Logo, apresentam-se as seguintes hipóteses:

\section{A) Hipóteses relacionadas ao profissionalismo $\mathrm{x}$ controle estatal}

$\mathrm{H}_{\mathrm{A} 1}=$ Os operadores da contabilidade brasileiros tendem a conferir ao poder estatal o poder da regulação da profissão contábil.

$\mathrm{H}_{\mathrm{A} 2}=$ Os operadores da contabilidade brasileiros tendem a ser menos independentes no tocante ao julgamento das práticas contábeis.

\section{B) Hipótese relacionada a uniformidade $\mathrm{x}$ flexibilidade}

$\mathrm{H}_{\mathrm{B} 1}=$ Os operadores da contabilidade brasileiros tendem a ser mais uniformes no tocante às práticas contábeis.

\section{C) Hipótese relacionada ao conservadorismo $\mathrm{x}$ otimismo}

$\mathrm{H}_{\mathrm{Cl}}=$ Os operadores da contabilidade brasileiros tendem a ser mais conservadores no tocante às práticas contábeis.

\section{D) Hipótese relacionada ao sigilo $\mathrm{x}$ transparência:}

$\mathrm{H}_{\mathrm{D} 1}=$ Os operadores da contabilidade brasileiros tendem a ser mais conservadores no tocante às práticas contábeis. 


\section{Procedimentos Metodológicos}

O universo da pesquisa foi formado por todos os operadores da contabilidade com dados disponíveis (incluindo $e$-mail). $\mathrm{O}$ instrumento foi disponibilizado virtualmente por meio da ferramenta Google Docs, sendo que convites para a participação na pesquisa foram enviados via e-mail. Além da replicação do questionário aos e-mails cadastrados, foi adotada a técnica da bola de neve. Ela consiste em solicitar que os respondentes encaminhem o instrumento de coleta de dados a seus pares, de modo a contribuir com a investigação (Collins \& Hussey, 2005). Essa técnica, todavia, tem como limitação selecionar a amostra por conveniência e por ser não probabilística.

Tendo em vista os objetivos desta pesquisa, aplicou-se um questionário estruturado com perguntas diretas aos operadores da contabilidade utilizado, originalmente, por Chanchani e Willett (2004) e replicado por Almeida e Lisboa (2011) e Karabinar, Canel e Öktem (2012) para capturar os valores contábeis. Para capturar a dimensão cultural, utilizou-se o Valued Survery Model (VSM) 08, construído por Hofstede (2008), e sua versão em português.

Como o instrumento para capturar os valores contábeis encontrava-se escrito em língua inglesa, foi necessária a sua tradução ao vernáculo brasileiro e sua adaptação cultural. Para isso, realizaram-se os seguintes passos: (i) inicialmente o questionário foi traduzido para o português; (ii) para verificar se houve alguma perda semântica no processo de tradução, a versão traduzida foi entregue a três professores doutores em Contabilidade; e (iii) após os ajustes sugeridos por eles, constituiu-se um único questionário. Após essa etapa e os ajustes necessários, chegou-se ao questionário final usado nesta investigação, seguidas de escala de Likert com cinco níveis. Para cada afirmação, o respondente assinalou uma única resposta e que corresponderia a seu grau de concordância, podendo variar de 1 (concordo totalmente) a 5 (discordo totalmente).

\begin{tabular}{|c|c|}
\hline Práticas Contábeis & Perguntas \\
\hline \multirow{4}{*}{$\begin{array}{l}\text { Conservadorismo } \\
{[\mathrm{CON}]}\end{array}$} & A profissão contábil deve ser autorregulada. \\
\hline & Contadores são os melhores avaliadores da posição financeira e do desempenho da entidade. \\
\hline & Contadores são os melhores avaliadores sobre o que divulgar nas demonstrações financeiras. \\
\hline & Contadores devem manter um elevado padrão de conduta ética. \\
\hline \multirow{4}{*}{$\begin{array}{l}\text { Sigilo } \\
{[S I G]}\end{array}$} & $\begin{array}{l}\text { Demonstrações financeiras devem estar disponíveis para o público em geral e não apenas para } \\
\text { os acionistas e gestores. }\end{array}$ \\
\hline & $\begin{array}{l}\text { Apenas uma quantidade mínima de informações detalhadas deve ser incluída nas } \\
\text { demonstrações financeiras. }\end{array}$ \\
\hline & Informações sobre a gestão e os acionistas não devem ser incluídas nas demonstrações financeiras. \\
\hline & Previsões feitas pelos gestores devem ser incluídas nas demonstrações financeiras. \\
\hline \multirow{4}{*}{$\begin{array}{l}\text { Profissionalismo } \\
\text { [PROF] }\end{array}$} & $\begin{array}{l}\text { Regras de depreciação devem ser definidas por órgãos reguladores externos às entidades, } \\
\text { especificamente para grupos distintos de ativos. }\end{array}$ \\
\hline & As demonstrações financeiras de todas as empresas devem ter uma mesma estrutura padronizada. \\
\hline & As políticas contábeis, uma vez definidas, não devem ser alteradas. \\
\hline & Havendo inflação o método de avaliação de estoque UEPS deve ser usado ao invés do PEPS. \\
\hline \multirow{4}{*}{ Uniformidade [UNI] } & Em situações de mensuração igualmente válidas, ativos e receitas devem ser subavaliados. \\
\hline & Valor de mercado é geralmente menos relevante do que o custo histórico. \\
\hline & De forma geral, o valor de mercado deve ser usado em vez de custo histórico. \\
\hline & O nível de detalhamento da normatização das demonstrações financeiras deve ser aumentado. \\
\hline
\end{tabular}

Figura 3. Questionário usado para capturar as práticas contábeis

Fonte: Chanchani e Willett (2004) - com adaptações 
No tocante às dimensões culturais, recorreu-se ao questionário Valued Survery Model 08 (VSM 08) adaptado, construído por Hofstede (2008), e sua versão em português. A adaptação foi necessária tendo em vista que o VSM 08, originalmente, busca capturar outros constructos - como o pragmatismo e a indulgência - que não são objeto desta investigação. Para cada afirmação, seguidas de escala de Likert com cinco níveis, o respondente assinalou uma única resposta de acordo com a situação apresentada podendo variar de 1 a 5. Assim, o questionário usado para capturar as dimensões culturais é apresentado na figura 4:

\begin{tabular}{|c|c|}
\hline $\begin{array}{l}\text { Dimensões } \\
\text { Culturais }\end{array}$ & Perguntas \\
\hline \multirow{4}{*}{$\begin{array}{l}\text { Distância do Poder } \\
\text { [PDI] }\end{array}$} & Ter um chefe (superior direto) que respeite. \\
\hline & Ser consultado pelo seu superior direto nas decisões envolvendo o seu trabalho. \\
\hline & $\begin{array}{l}\text { Na sua experiência profissional, qual a frequência com que os subordinados têm medo de } \\
\text { contradizer o chefe? }\end{array}$ \\
\hline & $\begin{array}{l}\text { È importante evitar, a todo custo, uma estrutura organizacional em que alguns subordinados } \\
\text { tenham dois chefes. }\end{array}$ \\
\hline \multirow{4}{*}{$\begin{array}{l}\text { Masculinidade } \\
\text { [MAS] }\end{array}$} & Ser reconhecido por bom desempenho. \\
\hline & Ter pessoas agradáveis com quem trabalhar. \\
\hline & Viver em uma área desejada. \\
\hline & Ter possibilidades de promoção. \\
\hline \multirow{4}{*}{ Individualismo [IND] } & Ter tempo suficiente para a sua vida pessoal ou familiar. \\
\hline & Ter segurança de emprego. \\
\hline & Fazer um trabalho interessante. \\
\hline & Ter um trabalho respeitado pela sua família e amigos. \\
\hline \multirow{4}{*}{$\begin{array}{l}\text { Aversão à Incerteza } \\
\text { [UAI] }\end{array}$} & Com que frequência se sente nervoso ou tenso no seu trabalho? \\
\hline & Em termos gerais, como descreve o seu atual estado de saúde? \\
\hline & $\begin{array}{l}\text { Pode ser um bom gestor sem ter uma resposta exata a todas as perguntas que um subordinado } \\
\text { possa fazer relativas ao trabalho dele. }\end{array}$ \\
\hline & $\begin{array}{l}\text { As regras de uma empresa ou organização não devem ser desrespeitadas, nem mesmo quando } \\
\text { o empregado achar que ao fazer isso beneficiaria a empresa ou organização. }\end{array}$ \\
\hline
\end{tabular}

Figura 4. questionário usado para capturar as dimensões culturais

Fonte: Hofstede (2008)- com adaptações

Ainda em relação ao instrumento, é importante destacar que foi formado por três seções principais. A primeira buscou capturar as dimensões culturais; a segunda, os valores contábeis; e a última seção capturou informações sobre o perfil do respondente com 4 perguntas. As informações sobre o perfil envolviam a autoinclusão na categoria de operador da contabilidade (o respondente assinalava se preferia se apresentar como aluno, professor, profissional ou usuário da contabilidade), sua escolaridade, a idade em anos completos e o gênero.

Tendo em vista que há um número diversificado de variáveis para capturar as dimensões culturais e aos valores contábeis com os operadores da contabilidade, recorreu-se à Analise Fatorial Exploratória (AFE). Os fatores foram extraídos por meio da Análise dos Componentes Principais e com extração Varimax. Na figura 5, são apresentados as condições de aceitabilidade para a análise fatorial.

\begin{tabular}{cll}
\hline Etapa & \multicolumn{1}{c}{ Técnica } & \multicolumn{1}{c}{ Regra para validação } \\
\hline \multirow{3}{*}{ 1. Dimensionalidade } & Componentes Principais & Existência de somente um autovalor \\
\cline { 2 - 3 } & Índice Kaiser-Meyer-Olkin (KMO) & KMO > 0,50: aceitável \\
\cline { 2 - 3 } & Esfericidade de Bartlett & Nível de significância baixo \\
\hline
\end{tabular}

Figura 5. Condições de aceitabilidade para a análise fatorial

Fonte: Hair, Black, Babin, Anderson e Tatham (2009) 
Após a análise fatorial, foi realizada uma regressão múltipla com os fatores extraídos, em que a variável dependente foram os constructos que representam as práticas contábeis, e as variáveis independentes corresponderem aos constructos que representam as dimensões culturais. Assim, é apresentado abaixo o modelo econométrico a ser usado nessa investigação, baseado no recorte teórico.

Profissionalismo $=f($ Individualismo; Aversão a Incerteza; Distância do Poder $)$

Uniformidade $=f$ (Individualismo; Aversão a Incerteza; Distância do Poder)

Conservadorismo $=f($ Individualismo; Aversão a Incerteza; Masculinidade $)$

Sigilo $=f($ Individualismo; Aversão a Incerteza; Masculinidade, Distância do Poder $)$

Abaixo é apresentada uma figura com os sinais esperados para os coeficientes da regressão de acordo com o recorte teórico, considerando o Brasil.

\begin{tabular}{lcccc}
\hline \multirow{2}{*}{$\begin{array}{c}\text { Dimensões Culturais } \\
\text { (Hofstede) }\end{array}$} & Profissionalismo & Uniformidade & Conservadorismo & Sigilo \\
\cline { 2 - 5 } & + & + & $?$ & + \\
\hline Distância do Poder & + & + & + & + \\
\hline Aversão à Incerteza & - & - & - & - \\
\hline Individualismo & $?$ & $?$ & - & - \\
\hline Masculinidade & & & & \\
\hline
\end{tabular}

Figura 06. Relação entre as dimensões culturais de Hofstede (1980) e as Práticas Contábeis de Gray (1988) considerando o Brasil

Fonte: Baydoun e Willet (1995) - com adaptações

\section{4 . Análise e Discussão dos Resultados}

A amostra final contou com um total de 449 respondentes, de todo o Brasil, com dados coletados entre outubro de 2013 a junho de 2014 e sua caracterização pode ser vista na Tabela 1.

Tabela 01

\section{Estatísticas dos respondentes}

\begin{tabular}{lcccc}
\hline \multirow{2}{*}{ Grau de Escolaridade } & \multicolumn{2}{c}{ Gênero } & Total \\
\cline { 2 - 5 } & Feminino & Masculino & Absoluto & em \% \\
\hline Doutorado & 1 & 7 & 8 & $1,78 \%$ \\
\hline Graduação completa & 50 & 93 & 143 & $31,85 \%$ \\
\hline Graduação incompleta & 31 & 41 & 72 & $16,04 \%$ \\
\hline Mestrado & 15 & 32 & 47 & $10,47 \%$ \\
\hline Mestrado incompleto & 0 & 1 & 173 & $0,22 \%$ \\
\hline $\begin{array}{l}\text { Pós Graduação } \\
\text { (especialização, MBA) }\end{array}$ & 77 & 96 & $\mathbf{3}$ & $\mathbf{3}, 53 \%$ \\
\hline Técnico em Contabilidade & 2 & 3 & 449 & $1,11 \%$ \\
\hline Total & 176 & 273 & $100,00 \%$ \\
\hline
\end{tabular}




\begin{tabular}{lcccc}
\hline \multirow{2}{*}{ Categoria de Operadores } & \multicolumn{2}{c}{ Gênero } & \multicolumn{2}{c}{ Total } \\
\cline { 2 - 5 } & Feminino & Masculino & Absoluto & em \% \\
\hline Aluno de Contabilidade & 31 & 37 & 68 & $15,14 \%$ \\
\hline Professor de Contabilidade & 13 & 39 & 52 & $11,58 \%$ \\
\hline $\begin{array}{l}\text { Profissional da } \\
\text { Contabilidade }\end{array}$ & 122 & 188 & 310 & $69,04 \%$ \\
\hline Usuário da Contabilidade & 10 & 9 & 19 & $4,23 \%$ \\
\hline Total & 176 & 273 & 449 & $100 \%$ \\
\hline
\end{tabular}

Fonte: elaboração própria a partir dos dados da pesquisa

Uma análise de componentes principais foi conduzida nos 32 itens do instrumento com rotação ortogonal (Varimax) e realizada para cada dimensão cultural e prática contábil. De acordo com Hair et al. (2009), espera-se que seja construído um único fator para cada constructo. Abaixo seguem os resultados da adequação da AFE.

Tabela 2

\section{Adequação da análise fatorial para os valores contábeis e dimensões culturais}

\begin{tabular}{|c|c|c|c|}
\hline \multirow{3}{*}{ Fatores } & \multicolumn{3}{|c|}{ Testes para verificar a aplicabilidade da Análise Fatorial Exploratória } \\
\hline & \multicolumn{3}{|c|}{ Dimensionalidade } \\
\hline & Componentes Principais & KMO & Bartlett \\
\hline PDI & \multirow{8}{*}{ Apenas um autovalor foi encontrado } & 0,50 & 0,00 \\
\hline MASC & & 0,61 & 0,00 \\
\hline IND & & 0,65 & 0,00 \\
\hline UAI & & 0,50 & 0,00 \\
\hline CONS & & 0,59 & 0,00 \\
\hline SIG & & 0,52 & 0,00 \\
\hline PROF & & 0,56 & 0,00 \\
\hline UNIF & & 0,50 & 0,00 \\
\hline
\end{tabular}

Fonte: elaboração própria a partir dos dados da pesquisa

Conforme os dados da Tabela 2, para cada fator, extraiu-se somente um fator. Quanto à estatística KMO, todos os fatores apresentaram valores igual ou superior a 0,50 , indicando, assim, a sua aceitabilidade. Com relação ao teste de esfericidade de Bartlett, verifica-se que, a um nível de confiança de 95\%, todos os fatores são significativos.

A tabela 3 apresenta a Estatística descritiva dos fatores

Tabela 3

\section{Estatísticas Descritivas dos fatores}

\begin{tabular}{|c|c|c|c|c|c|c|c|c|}
\hline \multirow{2}{*}{ Estatísticas } & \multicolumn{8}{|c|}{ Fatores } \\
\hline & PDI & MASC & IND & UAI & CONS & SIG & PROF & UNIF \\
\hline Média & 0,00 & 0,00 & 0,00 & 0,00 & 0,00 & 0,00 & 0,00 & 0,00 \\
\hline Mediana & 0,15 & 0,13 & 0,27 & 0,03 & 0,12 & 0,09 & 0,02 & $-0,03$ \\
\hline Variância & 1,00 & 1,00 & 1,00 & 1,00 & 1,00 & 1,00 & 1,00 & 1,00 \\
\hline Mínimo & $-5,14$ & $-3,77$ & $-4,23$ & $-3,14$ & $-5,13$ & $-1,69$ & $-2,65$ & $-2,44$ \\
\hline Máximo & 1,26 & 1,06 & 0,93 & 2,38 & 1,20 & 2,82 & 2,42 & 2,64 \\
\hline
\end{tabular}

Fonte: elaboração própria a partir dos dados da pesquisa 
Conforme os dados da Tabela 3, verifica-se que todos os fatores apresentam valores 0 e 1 para a média e o desvio padrão, respectivamente, indicando que essas variáveis são normalmente distribuídas.

Tabela 4

Resultado final para o modelo Profissionalismo = $f$ (Individualismo; Aversão a Incerteza; Distância do Poder)

\begin{tabular}{|c|c|c|c|c|}
\hline \multirow{2}{*}{ Coeficientes } & \multirow{2}{*}{ Valor } & \multirow{2}{*}{$\mathbf{t}$} & \multirow{2}{*}{ Sig. } & Estatística de Colinearidade \\
\hline & & & & VIF \\
\hline (Constante) & $-0,08$ & $-0,18$ & 0,85 & NA \\
\hline PDI & 0,16 & 3,01 & $0,00 * * \star$ & 1,31 \\
\hline UAI & 0,10 & 2,34 & $0,01 * *$ & 1,00 \\
\hline IND & 0,04 & 0,84 & 0,39 & 1,31 \\
\hline \multicolumn{5}{|c|}{ Resumo do Modelo } \\
\hline R quadrado ajustado (\%) & Durbin-Watson & & Análise da & riância - ANOVA \\
\hline $4 \%$ & 1,92 & 7.80 & Sig. & 0,000 \\
\hline
\end{tabular}

** Significativo a um nível de confiança de $95 \%$

***Significância a um nível de confiança de $99 \%$

Fonte: dados da pesquisa

A Tabela 4 apresenta os resultados finais das estatísticas para profissionalismo como variável dependente e como variáveis independentes a distância do poder, aversão à incerteza e individualismo, estimados por meio do software GRETL por meio do método dos Mínimos Quadrados Ordinário (OLS). Tendo em vista que a modelagem econométrica por meio do OLS tradicional apresentou problemas de heterocedasticidade, adotou-se a modelagem econométrica por meio dos Mínimos Quadrados Ordinário (OLS) com a heterocedasticidade corrigida. Para detectar a existência de autocorrelação entre os resíduos, foi aplicado o teste de Durbin-Watson. De acordo com Field (2009), os valores para essa estatística próximo a 2 correspondem à não existência de autocorrelação entre os resíduos. O teste de Multicolinearidade foi realizado por meio do teste de Fator de Inflação da Variância (VIF), e verificou-se que o modelo está dentro de uma multicolinearidade aceitável.

A variável IND não apresentou significância estatística e, além disso, seu sinal não está indo ao encontro do recorte teórico aqui levantado para os operadores da contabilidade brasileiros, ou seja, que eles não dão preferência para um julgamento profissional independente, evidenciado, assim, um certo descasamento da proposição de Gray (1988) com a realidade, como evidenciado nas pesquisas de Tsakumis (2007) e Almeida e Lisboa (2011). Entretanto, embora sem significância estatística, o sinal desse constructo evidencia, em certo ponto, uma preferência por um julgamento profissional independente por parte dos operadores da contabilidade brasileiros entrevistados. Até certo ponto, isso é relevante, pois um julgamento independente está mais alinhado com as práticas contábeis internacionais às quais a contabilidade brasileira adequou-se a partir da Lei n. ${ }^{\circ}$ 11.638/2007 Nesse sentido, os dados apontam uma certa tendência de uma independência por parte dos operadores da contabilidade no que diz respeito à operação da contabilidade, permitindo, assim, um julgamento mais liberto acerca do fenômeno econômico observado em uma entidade. Assim, não se pode aceitar a Hipótese $\mathrm{H}_{\mathrm{A} 1}$ 
Por outro lado, os fatores PDI e UAI apresentam significância estatística e os sinais dos seus coeficientes vão ao encontro do recorte teórico aqui levantado para os operadores da contabilidade no Brasil. Nesse sentido, observa-se uma forte relação entre o profissionalismo e distância do poder, o que indica uma falta de preocupação com direitos igualitários para todos; proporciona que as pessoas dos vários níveis de poder se sintam mais ameaçadas e menos preparadas para confiar nas outras; e demonstra uma convicção maior da necessidade de justificar a imposição de leis e regulamentos. No tocante à Contabilidade, isso indica que, em certa medida, os operadores da contabilidade entrevistados preferem dar ao poder estatal a competência para a regulação da profissão contábil. Tal ideia fica mais evidente quando se verifica o constructo UAI, pelo qual se percebe uma forte relação com o profissionalismo indicando uma descrença no jogo justo, em que uma variedade de julgamentos profissionais tende a não ser facilmente tolerada (Gray, 1988). Logo, não se pode rejeitar a hipótese $\mathrm{H}_{\mathrm{A} 2}$.

Tabela 5

Resultado final para o modelo Uniformidade $=f$ (Individualismo; Aversão a Incerteza; Distância do Poder)

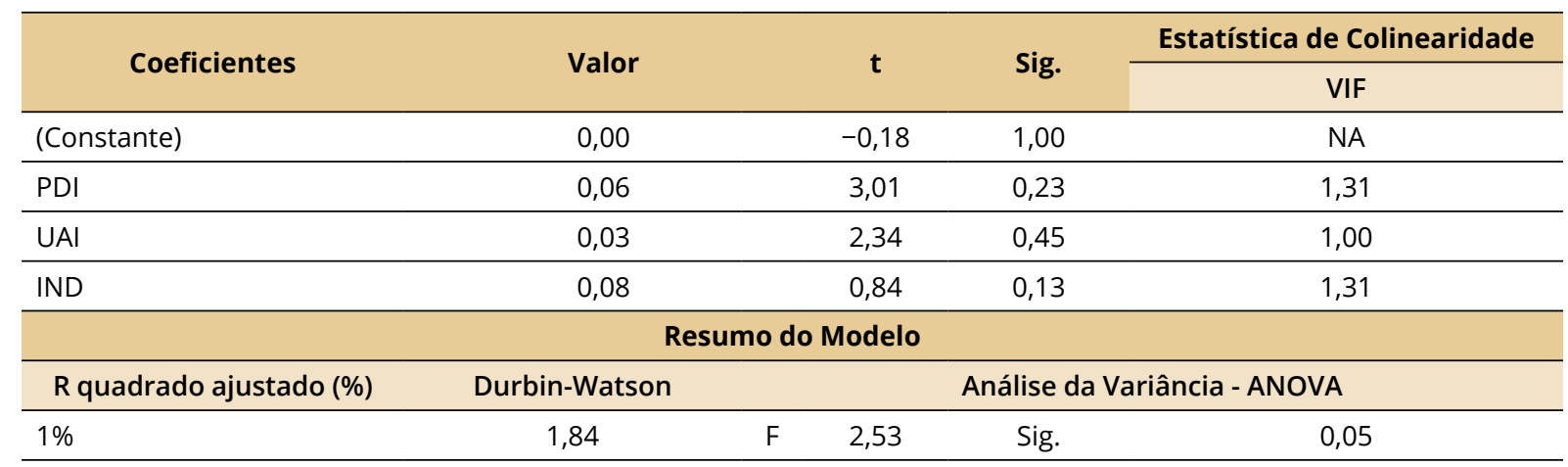

Fonte: Dados da pesquisa

A Tabela 5 apresenta os resultados finais das estatísticas para uniformidade como variável dependente e como variáveis independentes a distância do poder, aversão à incerteza e individualismo, estimados por meio do software GRETL por meiodo método dos Mínimos Quadrados Ordinário (OLS). Para detectar a existência autocorrelação entre os resíduos, foi aplicado o teste de Durbin-Watson. De acordo com Field (2009), os valores para essa estatística próximo a 2 correspondem à não existência de autocorrelação entre os resíduos. O teste de Multicolinearidade foi realizado por meio do teste de Fator de Inflação da Variância (VIF), e verificou-se que o modelo está dentro de uma multicolinearidade aceitável.

Embora não significativo, o sinal positivo do constructo UAI demonstra certa tendência dos operadores da contabilidade para a aversão à incerteza, o que indica uma prática contábil preocupada com a lei, a ordem e códigos rígidos e escritos de comportamento e evidencia, dessa forma, uma tendência de práticas contábeis uniformes, o que limita, em certo ponto, um melhor reporte do fenômeno econômico passível de registro, mensuração e evidenciação por parte da contabilidade. Além disso, isso vai de encontro ao que preconiza as práticas contábeis internacionais, cuja principal característica é o registro do fenômeno econômico de acordo com a sua essência e, não, de acordo com os seus aspectos formais. Tal fato fica mais evidente quando se verifica a relação positiva entre a distância do poder e uniformidade, já que a imposição de leis e códigos é em caráter uniforme e emana de um grupo detentor do poder político, evidenciando, assim, a não participação significativa dos operadores da contabilidade da regulação contábil. Por fim, cabe comentar quanto à relação entre individualismo e uniformidade. Ao contrário dos outros constructos, que apresentaram sinais positivos e de acordo com o que se esperava para os operadores da contabilidade brasileiros, esse apresentou sinal positivo indicando, em certo ponto, uma preferência por um julgamento profissional independente por parte dos operadores da contabilidade brasileiros quanto à uniformidade das práticas contábeis, embora sem significância estatística. Logo, não se pode aceitar, por completo, a hipótese $\mathrm{H}_{\mathrm{B} 1}$. 
Tabela 6

Resultado final para o modelo Conservadorismo = $f$ (Individualismo; Aversão a Incerteza; Masculinidade)

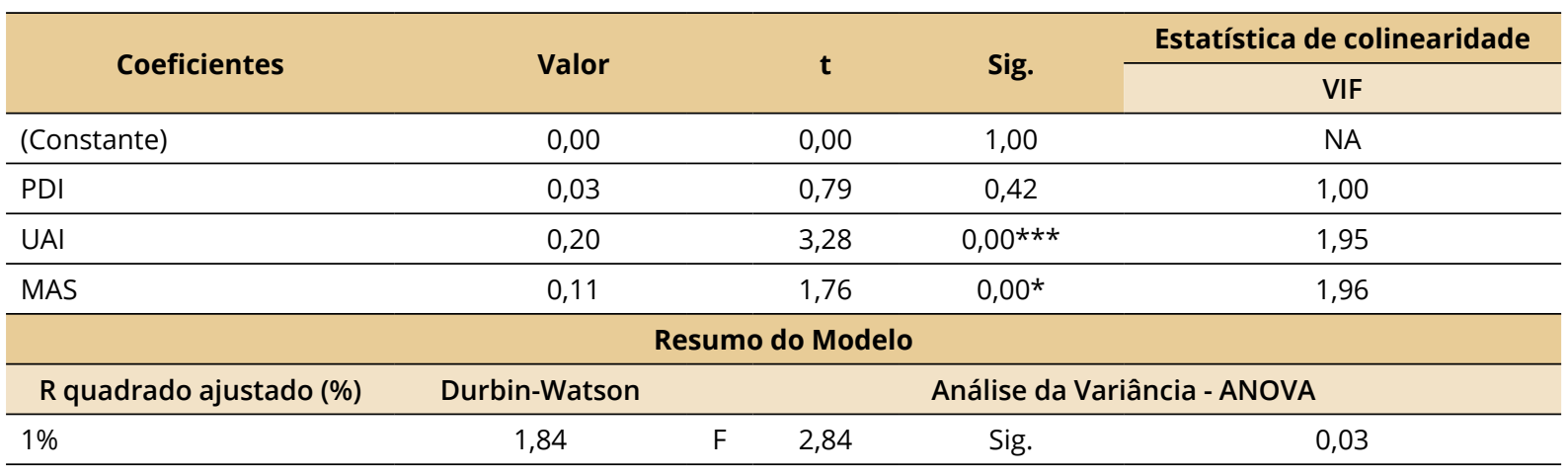

Fonte: dados da pesquisa

A Tabela 6 apresenta os resultados finais das estatísticas para o conservadorismo como variável dependente e como variáveis independentes a distância do poder, aversão à incerteza e masculinidade, estimados por meio do software GRETL por meio do método dos Mínimos Quadrados Ordinário (OLS). Para detectar a existência de autocorrelação entre os resíduos, foi aplicado o teste de Durbin-Watson. De acordo com Field (2009), os valores para essa estatística próximo a 2 correspondem à não existência de autocorrelação entre os resíduos. O teste de Multicolinearidade foi realizado por meio do teste de Fator de Inflação da Variância (VIF), e, verificou-se que o modelo está dentro de uma multicolinearidade aceitável.

Gray (1988) explica que a ligação entre o conservadorismo e as dimensões propostas por Hofstede (1980) estão mais fortemente relacionadas com a aversão à incerteza e menos intensas em relação à distância do poder e masculinidade, tendo em vista que sociedades com essa característica elevada, tendem a ser mais cautelosas e prudentes no tocante ao processo contábil e, de acordo com a Tabela 06, essa associação encontra-se perfeitamente evidenciada tanto em termos de sinais quanto em significância estatística. Logo, verifica-se que os operadores da contabilidade entrevistados dão preferência por mensurações mais conservadoras ao auferir os lucros, seguindo uma preocupação com segurança e prudência e uma necessidade perceptível em adotar medidas cautelosas para conter incertezas futuras. Assim, aceita-se a hipótese $\mathrm{H}_{\mathrm{Cl}}$

Por outro lado, esperavam-se sinais negativos para os coeficiente dos fatores PDI e MAS diante do cenário cultural brasileiro proposto por Hofstede (1980). Sociedades com baixa distância do poder evidenciam cidadãos mais otimistas (e, portanto, menos conservadores) se comparadas com aquelas com uma elevada distância do poder. Assim, esperava-se, para os entrevistados, uma associação positiva entre a distância do poder e conservadorismo, algo que é verificado, embora sem significância estatística. Além disso, as sociedades masculinas enfatizam a realização financeira e pessoal, ambição pelo desempenho e a tentativa em se sobressair em detrimento ao coletivo, indicando, pois, uma certa tendência a individualidade. No tocante a sua relação com o conservadorismo, espera-se que haja uma relação inversa o que, entretanto, não é evidenciada nos achados dessa investigação. 
Tabela 7

Resultado final para o modelo Sigilo = (Individualismo; Aversão a Incerteza; Masculinidade, Distância do Poder)

\begin{tabular}{|c|c|c|c|c|}
\hline \multirow{2}{*}{ Coeficientes } & \multirow{2}{*}{ Valor } & \multirow{2}{*}{$\mathbf{t}$} & \multirow{2}{*}{$\begin{array}{l}\text { Sig. } \\
\text { VIF }\end{array}$} & \multirow{2}{*}{$\frac{\text { Estatística de colinearidade }}{\text { VIF }}$} \\
\hline & & & & \\
\hline (Constante) & 0,00 & 0,00 & 1,00 & NA \\
\hline UAI & 0,03 & 0,63 & 0,52 & 1,01 \\
\hline PDI & 0,05 & 0,89 & 0,37 & 2,06 \\
\hline MAS & 0,05 & 0,76 & 0,44 & 2,08 \\
\hline IND & $-0,11$ & $-1,63$ & 0,10 & 1,39 \\
\hline \multicolumn{5}{|c|}{ Resumo do Modelo } \\
\hline R quadrado ajustado (\%) & Durbin-Watson & \multicolumn{3}{|c|}{ Análise da Variância - ANOVA } \\
\hline $4 \%$ & 1,83 & 2,84 & Sig. & 0,45 \\
\hline
\end{tabular}

Fonte: Dados da pesquisa

A Tabela 7 apresenta os resultados finais das estatísticas para sigilo como variável dependente e como variáveis independentes a distância do poder, aversão à incerteza e masculinidade e individualismo, estimados por meio do software GRETL e por meio do método dos Mínimos Quadrados Ordinário (OLS). Para detectar a existência de autocorrelação entre os resíduos, foi aplicado o teste de Durbin-Watson. De acordo com Field (2009), os valores para essa estatística, próximo a 2 correspondem à não existência de autocorrelação entre os resíduos. O teste de Multicolinearidade foi realizado por meio do teste de Fator de Inflação da Variância (VIF), e verificou-se que o modelo está dentro de uma multicolinearidade aceitável.

Verifica-se que nenhum dos fatores apresentou significância estatística, apesar de que os constructos "aversão à incerteza" e "distância do poder" apresentaram coeficientes com sinais positivos, e que, nesse sentido, vai ao encontro do recorte teórico aqui proposto para o Brasil, indicando, de certo modo, uma preferência pela sigilosidade das informações ofertadas.

Gray (1988) afirma que o sigilo é consistente com uma preferência ao coletivismo, devido ao maior envolvimento com a companhia em lugar de partes externas. Além disso, a ligação íntima em sociedades com uma elevada distância do poder também é inegável, uma vez que essa dimensão é caracterizada pela restrição de informação para preservar desigualdades de poder. Logo, pode-se aceitar, mesmo que parcialmente, a hipótese $H_{D 1}$.

A seguir é apresentada a figura 7 com as principais conclusões acerca das hipóteses levantadas:

\begin{tabular}{|c|c|}
\hline Hipóteses & Resultado \\
\hline $\begin{array}{l}\text { HA1 = Os operadores da contabilidade brasileiros tendem a conferir ao poder estatal o } \\
\text { poder da regulação da profissão contábil. }\end{array}$ & Aceita Parcialmente \\
\hline $\begin{array}{l}\text { HA2 = Os operadores da contabilidade brasileiros tendem a ser menos independentes no } \\
\text { tocante ao julgamento das práticas contábeis. }\end{array}$ & Não Aceita \\
\hline $\begin{array}{l}\text { HB1 = Os operadores da contabilidade brasileiros tendem a ser mais uniformes no tocante } \\
\text { às práticas contábeis. }\end{array}$ & Aceita Parcialmente \\
\hline $\begin{array}{l}\text { HC1 = Os operadores da contabilidade brasileiros tendem a ser mais conservadores no } \\
\text { tocante às práticas contábeis. }\end{array}$ & Aceita \\
\hline $\begin{array}{l}\text { HD1 = Os operadores da contabilidade brasileiros tendem a ser mais sigilosos no tocante às } \\
\text { práticas contábeis. }\end{array}$ & Aceita Parcialmente \\
\hline
\end{tabular}

Figura 7. Resultado dos testes de hipóteses

Fonte: dados da pesquisa. 


\section{Conclusão}

O objetivo desse estudo foi verificar em que extensão as dimensões culturais impactam as práticas contábeis no Brasil. Os resultados aqui alcançados indicam que os operadores da contabilidade entrevistados são principalmente conservadores, e os valores culturais que mais impactam a prática contábil são "aversão à incerteza" e "distância do poder".

Cabe salientar que o estudo aqui levantado não levou em consideração as especificações da Ciência Contábil que pode ser um tanto quanto rígidas (como, por exemplo, a aplicada ao setor público), ou aquela mais flexíveis (como, a gerencial). Todavia, a depender da atuação e da maneira com que se lida com cada especificação da ciência contábil, isso pode sofrer variações. Além disso, apesar de ser uma pesquisa que contemplou operadores da contabilidade de todo o Brasil, os dados devem ser considerados no contexto dos respondentes.

Com os dados obtidos, percebe-se que, em um primeiro momento, não existe uma congruência entre os valores preconizados nas normas contábeis internacionais com o que percebido pelos agentes responsáveis por sua execução, pois proporciona uma melhoria no processo contábil, em que essas normas originalmente foram concebidas (tradição jurídica do commom law), e apresentam uma baixa aversão à incerteza e à distância do poder, algo contrário do que foi encontrado nessa investigação, apesar de haver outros aspectos desses países que, nos achados da pesquisa, são congruentes, como a independência de julgamento. Assim, a investigação em tela contribui na discussão sobre como outros fatores - além do sistema legal e regulatório - influenciam o processo contábil em países emergentes e de tradição jurídica code Law, cuja característica principal é do reporte contábil que menos privilegia o mercado acionário, mas que é fortemente voltado para o atendimento dos aspectos normativos, proporcionando, assim, um menor reflexo da realidade econômica de forma satisfatória.

Como fatores limitadores da investigação e recomendações para futuras pesquisas, temos: (i) observa-se que os achados desta pesquisa, em alguns aspectos, divergem com o recorte teórico aqui apontado, sugerindo, assim, novas pesquisas com uma quantidade maior de participantes e com o uso de outras técnicas estatísticas, a exemplo da análise fatorial confirmatória; (ii) embora amplamente usado em pesquisas culturais, o constructo de Hofstede (1980), conforme já apontado anteriormente, é passível de críticas. Logo, recomenda-se o uso de outros instrumentos para a captura das dimensões culturais, tais como o Globe que contempla nove fatores para capturar a dimensão cultural; e (iii) a tradução ao vernáculo brasileiro e a adaptação cultural do instrumento para captura das práticas contábeis, embora revisadas por três doutores em Contabilidade, pode ter sido objeto de perda semântica. Nesse sentido, recomenda-se a utilização de outras escalas para a sua captura ou a construção de uma para o vernáculo brasileiro. Tal observação também vale para o instrumento de captura das dimensões culturais.

\section{Referências}

Almeida, C. \& Lisboa, I. P. de. (2011). The culture and the accounting values: an empirical study in view of portuguese preparers. Journal of International Business and Economics, 11(2), pp. 16-28.

Baydoun, N. \& Willett, R. (1995), Cultural Relevance of Western Accounting Systems to Developing Countries. Abacus, 31(1), pp. 67-92, doi: 10.1111/j.1467-6281.1995.tb00355.x

Baskerville, Rachel F.(2003). Hofstede never studied culture. Accounting Organization and Society. 28.pp $1-14$.

Chanchani, S. \& Willett, R. (2004a). An empirical assessment of Gray's accounting value constructs. The International Journal of Accounting, 39(2), pp. 125-154, doi:10.1016/j.intacc.2004.02.003

Chanchani, S. \& MacGregor, (1999). A. A synthesis of cultural studies in accounting. Jornal od Acoounting Literature, 18, pp. 1-30.. 
Chaui, Marilena. (2008). Cultura e democracia. In: Crítica y emancipación : Revista latinoamericana de Ciencias Sociales, 1(1). CLACSO. Recuperado em 31 março, 2015 de http://bibliotecavirtual.clacso. org.ar/ar/libros/secret/CyE/cye3S2a.pdf.

Collins, Jill \& Hussey, Roger.(2005) Pesquisa em administração - um guia prático para alunos de graduação e pós graduação. Trad. Lucia Simonini. (2a Ed.). Porto Alegre: Bookman,.

Ding, Y.; Jeanjean, T. \& Stolowy, H. (2005). Why do national GAAP differ from IAS? The role of culture. The International Journal of Accounting, 40(4), pp. 325-350, doi:10.1016/j.intacc.2005.09.004,

Eddie, I.A. (1990). Asia Pacific cultural values and accounting systems. Asia Pacific International Management Forum. 6, pp 22-30..

FIELD, Andy. (2009). Descobrindo a estatística usando o SPSS. 2a . ed. Porto Alegre: Bookman, 2009.

Gray, S. J. (1988). Towards a Theory of Cultural Influence on the Development of Accounting Systems Internationally. Abacus. doi: 10.1111/j.1467-6281.1988.tb00200.x

Hair, J. F; Black, W. C.; Babin, B. J.; Anderson, R. E. \& Tatham, R. L. (2009). Analise multivariada de dados. Tradução de Adonai Schlup Sant'Anna. $6^{\circ}$ ed. Porto Alegre: Bookman.

Harrison, G. L., \& McKinnon, J. L. (1986). Culture and accounting change: A new perspective on corporate reporting and accounting policy formulation. Accounting, Organizations and Society, 11, pp. 233-252. doi:10.1016/0361-3682(86)90023-1

Hofstede, G. (1980). Culture's consequences: International differences in work-related values. Beverly Hills; London: Sage Publications.

Hofstede, G. (2008). Módulo de inquérito sobre valores 2008. VSM08. Versão Portuguesa. Recuperado em 16/08/2016 de http://www.geerthofstede.nl/vsm-08.

Hopwood, A. \& Miller, P. (1994). Accounting as social and institutional practice. Cambridge University Press.

Karabinar, S; Canel, C. \& Öktem, R. (2012). A Survey of Acccounting Culture in Turkey. Advances in Management, 5(42), pp. 42-50.

Lei $\mathrm{n}^{\circ} 11.638$, de 28 de dezembro de 2007. Altera e revoga dispositivos da Lei no 6.404, de 15 de dezembro de 1976, e da Lei no 6.385, de 7 de dezembro de 1976, e estende às sociedades de grande porte disposições relativas à elaboração e divulgação de demonstrações financeiras. Brasília, DF. Recuperado em 16/08/2016 de http://www.planalto.gov.br/ccivil_03/_ato2007-2010/2007/lei/111638.htm

Nobes, Christopher. (1998). Towards a General Model of the Reasons for International Differences in Financial Reporting. Abacus, 34(2), pp. 162-187, doi: 10.1111/1467-6281.00028

Rodriguez, R. P. J. (2009). Three essays on the quantification Validation, and application of Gray' Accounting Values. University of Texas at El Paso - [S.1.].

Tsakumis, G. T. (2007). The influence of culture on accountants' application of financial reporting rules. Abacus, 43(1), pp. 27-48, doi:10.1111/j.1467-6281.2007.00216.x

Weffort, Elionor Farah Jreige. (2005). O Brasil e a Harmonização Contábil Internacional. São Paulo, SP, Atlas. 